\title{
The Impact of Virtual Employment Interviews on the Teacher Hiring Process
}

\section{Laurie Kimbrel, Ed.D. University of West Georgia}

\begin{abstract}
The purpose of this qualitative study was to understand the perceptions of school administrators regarding the benefits of the virtual teacher hiring processes adopted when in-person interviews were impossible due to COVID19. Specifically, this research investigated the ways that teacher hiring changed during school closures and the extent to which those changes reflected best practice, whether school leaders felt that their virtual interviews were effective, and how leaders believe the experience of hiring using virtual interviews would change future teacher selection processes. Semi-structured interviews served as the data collection tool and a sequential process of first and second cycle coding were used to analyze interview transcripts. Results indicated when school leaders used virtual interviews, they were forced to adopt more reliable teacher selection practices, including careful screening of resumes, interview questions designed to uncover values and effective teaching behaviors, authentic assessment of skills, and attention to teaching artifacts in digital portfolios. School leaders did not intentionally align their new selection processes with research-based best practices, but they were aware of the practical value of the changes made to their hiring processes and indicated that they intended to maintain at least some of the practices in the future.
\end{abstract}

Keywords: teacher hiring, virtual interviews, teacher quality, teacher selection best practices

Classification: Education, Qualitative, Education Administration

cos

n early March of 2020, the teacher hiring season was barely underway when the novel coronavirus, COVID-19, began to spread throughout the United States. In response to rising infection rates, school leaders instituted what most believed would be temporary school closures. By mid-April, typically the peak of the teacher hiring season, school closure orders or recommendations for the remainder of the school year were in place in 48 states, the District of Columbia, and all five US territories (Chavez \& Moshtaghian, 2020). These indefinite school closures disrupted all school district operations, including the teacher hiring processes that begin in early spring with the recruitment of college graduates and end in late summer when the final teacher is hired.

School leaders were faced with many unknown factors during the pandemic related school closures, and they finished the 2019-2020 school year not knowing when and how their schools would reopen. The undetermined length of school closures forced principals to rethink teacher hiring processes, which typically rely on face-to-face interactions and in-person, conversational interviews (Kimbrel, 2019a). The traditional employment interview is the most commonly used tool for the selection of employees in industries and organizations across the United States (Crosby, 2000) and the field of 
education is no exception as most principals rely on interviews as their primary source of information regarding a candidate (Cannata et al., 2017). However, when face to face interviews were no longer possible, school leaders turned to virtual interviews as an alternative.

While the COVID-19 pandemic may be temporary, the lessons learned from hiring during a crisis are relevant to school leaders who must continue to work through unknown future events, whether they are as significant as a pandemic or catastrophic weather event or as routine as the day-to-day disruptive events and unexpected circumstances that regularly occur in schools. The effect of technology on all school processes, including teacher hiring, will not end when the pandemic is over. Consequently, it is important to consider the lasting impacts and benefits of changes first adopted out of necessity during the global health crisis.

\section{Literature Review}

\section{Teacher Hiring as an Element of School Improvement}

Research over the past decades has provided increasing evidence of the importance of a skillful teacher to ensure high levels of learning for each student (Darling-Hammond, 2000; Hattie, 2009; Marzano, 2003). Receiving instruction from a high- quality teacher has consistently been found to have a greater impact on students than other school and home level factors. Teachers have two to three times the impact of any other school factor, including programming, school leader, and technology access (Marzano, 2003). Despite the growing body of knowledge regarding the importance of teacher quality, the process of teacher recruitment and hiring is often an overlooked element of school improvement planning (Loeb, Beteille, \& Kalogrides, 2012).

Every opportunity to hire a new teacher is also an opportunity to improve the school and outcomes for students (Mertz, 2010) and the wrong hiring decisions move the school further away from improvement goals. Most principals agree that hiring effective teachers is one of their most important roles (Pillsbury, 2005) and that bad hiring decisions are detrimental to both student achievement and school culture (Loeb, Beteille, \& Kalogrides, 2012). Once a new teacher is hired, it is improbable that the teacher will be evaluated poorly or dismissed, even if the principal does not believe that teacher to be effective. Less than one-third of teachers perceived as ineffective by their principals are rated as such, and less than $1 \%$ of teachers are annually rated as unsatisfactory (Kraft \& Gilmour, 2017). Similarly, extremely low rates of teacher dismissals have remained constant over the past several decades. According to the Schools and Staffing Survey, the percentage of teachers dismissed each year has held constant at around 2\% from 1999 until the last time the survey was given in 2012 (National Center for Educational Statistics, n.d.). Principals recognize that a teacher's ability to deliver high-quality instruction is the most critical issue when assessing teacher performance, and yet principals view the teacher dismissal process as so difficult and time-consuming that teacher contract non-renewals are only pursued for the most egregious issues of incompetence and ethical violations (Nixon et al., 2020). Given the low rates of teacher dismissals and the connection of high-quality teachers to student outcomes, it is imperative that teacher selection processes accurately identify the candidates most likely to experience success.

\section{Reliance on Subjective Teacher Hiring Processes}

Most school principals are recruited from the ranks of teachers and are unlikely to have human resource training or experience, and yet in many school districts, hiring is a decentralized process where the individual principal is responsible for the creation of the hiring process and teacher selection decisions (Jacob, 2016). As a result, there is great variation in teacher hiring processes among schools. Some principals handle teacher selection in an impromptu manner based on expediency rather than best practices (Goldhaber, Grout, \& Huntington-Klein, 2014), and principals tend to select teachers based on their interpretation and perceptions of the candidate's competency, character, and chemistry (Bourke,

KIMBREL / DOI: 10.5929/2021.11.1.1 
2012) rather than developing mechanisms that will allow selection of the candidates who possess the specific instructional skills necessary to move the school community towards identified improvement goals (Mertz, 2010). In short, principals often hire teachers based on their intuition (Kersten, 2010) rather than valid judgments of teaching effectiveness (Murnane \& Steele, 2007).

The traditional conversational employment interview is among the most popular, yet also most unreliable elements of the selection process in any industry (Moore, 2017) and is particularly problematic in education because it offers minimal opportunity to accurately assess a teacher's pedagogical skills (Engel, 2013). The traditional conversational interview is not predictive of an employee's future success due to a combination of factors, including interviewer bias and the impact of first impressions, which are often the primary determinants of the successful applicant (Seagrest Purkiss et al., 2006). Many interviews are highly subjective, and some interviewer decisions are made within the first 30 seconds of meeting the candidate (Joyce, 2008). These quick judgments are often based on appearance, confidence, eye contact, enthusiasm, knowledge of the hiring organization, ability to sell oneself, and communication style, rather than responses to substantive questions or ability to perform well on the job. The interview process's validity and reliability can be greatly improved when there is a reduction of bias and inconsistency, which can be accomplished through the addition of elements of structure (Moore, 2017).

\section{Best Practice for Effective Teacher Selection}

While some textbooks and articles suggest best practices for hiring teachers, very few empirical studies definitively connect selection practices to teacher quality. Hiring practices in schools have not evolved at the same rate as hiring practices in other industries, and a recent nation-wide survey revealed that teacher selection processes often singularly focus on a review of application materials, such as resume and transcripts, rather than performance-based or predictive measures (Konoske-Graf, Partelow, Benner, 2016).

Selection science research from the management field provides direction regarding a selection process that is most predictive of success during employment. Because no single tool is perfect, and the traditional interview alone is unreliable (Hamdani, Valcea, \& Buckly, 2014), the literature advises the development and utilization of a multiple-step selection system. Moore (2017) identified three essential elements for an effective hiring process: (1) identification of key qualifications and prior experience necessary for success, (2) development of interview questions and acceptable answers that assess whether the candidates possess the identified values and skills, and (3) addition of other predictive elements such as authentic assessments or job-related artifacts.

\section{Theoretical Perspective}

This study is grounded in the literature regarding the connection between teacher quality and student outcomes. Specifically, the framework for this study is drawn from Darling- Hammond's (2000) work in which she connected teacher qualifications to student achievement using data from a 50-state survey of policies, state case study analyses, the 1993-94 Schools and Staffing Surveys (SASS), and the National Assessment of Educational Progress (NAEP). Darling-Hammond's findings from both her qualitative and quantitative analyses suggest that increases in teachers' quality are related to improvements in student performance.

Like others before her, Darling-Hammond found that a skillful teacher's impact on student achievement is stronger than student-level factors such as poverty, language background, and race. Darling-Hammond concluded that while other school improvement efforts such as curriculum development and textbook adoptions are important, they make little difference if teachers are not skillful at using these resources to meet their students' specific needs. Therefore, it stands to reason that efforts to improve teacher 
selection systems to identify the teachers most likely to impact student outcomes are an essential element of school improvement efforts.

\section{Problem Statement}

Given the long-standing and documented connection of high quality, skilled teachers to student learning, it is imperative that only the teachers who have the greatest probability of success are hired, rather than those who will maintain the status quo or perform poorly. The work of hiring high-quality teachers is an essential element of school improvement and must be pursued even during the most challenging circumstances, such as school closures and quarantines. The purpose of this qualitative study was to understand the perceptions of school administrators regarding the processes and outcomes of virtual teacher hiring processes while schools were closed due to the global pandemic during the spring and summer of 2020. Furthermore, the investigator sought information regarding school leaders' perceptions of the efficacy of their hiring processes, significant challenges, and how the pandemic hiring experience may inform future teacher selection processes.

\section{Research Questions}

The following questions guided this study:

1. How were teacher hiring processes changed to accommodate school closures and social distancing practices, and how do those changes reflect teacher selection best practices?

2. From the perspective of school administrators, how effective were hiring processes to identify high-quality teachers during the spring and summer of 2020 ?

3. How do school administrators anticipate that the virtual teacher hiring experience will change future teacher selection processes?

\section{Methodology}

A basic qualitative methodology was used in which semi-structured interviews were the primary data collection tool used to understand the phenomena of hiring from the perspective of school leaders. This method was used because qualitative research seeks to understand "how people interpret their experiences, how they construct their worlds, and what meaning they attribute to their experiences" (Merriam \& Tisdell, 2016, p. 6). Semi-structured interviews with open-ended questions were used so that the researcher understood the participants' experiences in their own words, and conceptual connections could occur throughout the data collection process. Additionally, care was taken during the coding process to ensure that the data collected reflected the participants' responses and not the researcher's biases.

\section{Research Context}

The participants in this study were school administrators from the southeast region of the USA. Purposeful sampling was used to select participants who met the criteria of direct involvement in the teacher hiring process during the spring and summer of 2020. Additionally, participants were sought from a variety of types of schools in various communities. The number of participants was determined by analyzing the data throughout the collection process to look for saturation in the responses. Saturation is the point where no new insights or themes are uncovered through continual data collection. Ultimately, saturation was securely reached after interviews with 14 participants. Of the 14 participants who completed the semi-structured interview process, two were principals, and twelve were assistant principals. One participant worked in a primary school setting, seven in the elementary school setting, two in middle school, and four in high schools. Six participants' schools were located in a rural setting, six in a suburban setting, and two in an urban setting. 


\section{Data Collection}

Participants for the interviews were recruited using a solicitation email sent to principals and assistant principals of public schools in the southeast region of the USA. Once participants indicated interest and their qualifications for the study were verified, appointments were made for approximately 30-minute phone interviews.

Questions for the interviews were developed from an extensive review of the literature and the research questions for this study. All questions were open responses so that participants could share their experiences in their own words and tell their own stories. An interview protocol was developed and used for each interview, but the nature of semi-structured interviews allowed for follow up questions. Questions were not necessarily asked in the same order, or if the participant had sufficiently answered the question within another response (Roulston, 2010). All interviews were conducted on the phone, and after seeking verbal consent from the participant, interviews were recorded. Recordings were transcribed into verbatim written documents by the researcher except that all identifying information for participants, their school, or teachers within their school were replaced with pseudonyms. Each participant's name was replaced with a number (1-14) as an identifier, and audio recordings of interviews were destroyed after transcripts were created.

\section{Data Analysis}

A sequential process of first and second cycle coding was used to analyze interview transcripts. Saldana (2016) describes first cycle coding as the process of assigning initial codes to units of data and second cycle coding as the work to arrange the first cycle codes into themes and categories. First and second cycle coding were completed using NVivo 12 for Windows software.

Transcripts were coded using a descriptive coding process that assigned words or short phrases as labels to categorize data into topics (Miles, Huberman, \& Saldana, 2020). First cycle codes were not predetermined but instead based on the language used by the participants. This decision was made to reduce researcher bias and so that all categories were considered, regardless of whether the researcher expected them. Simultaneously, a codebook was developed to track and define the short phrases that arose during the coding process.

After the first cycle coding was completed, the codes were arranged into theme areas according to the study's research questions. According to Miles, Huberman, \& Saldana (2020), second cycle coding is a method to group the initial codes into a smaller number of categories to explain a bigger picture. The purpose of second cycle coding in this study was to align the findings with the research questions for the study and determine the connection with the established theoretical framework. Once categories were arranged into themes, themes were categorized as expected, unexpected, and themes of conceptual interest as suggested by Creswell \& Cresswell (2018). The categorization of themes is included in the discussion section of this paper.

\section{Results}

\section{First Cycle Data Coding}

The first cycle codes and their frequencies are provided in Table I. Codes are listed in the order of the hiring process from recruitment through hiring outcomes and future plans. 
Table I

\section{Results from First Cycle Descriptive Coding}

\begin{tabular}{|c|c|c|}
\hline Code & $\begin{array}{l}\text { Number of transcripts in } \\
\text { which the code appears }\end{array}$ & $\begin{array}{l}\text { Number of total } \\
\text { references within the } \\
\text { entire data set }\end{array}$ \\
\hline Recruitment - events canceled & 9 & 9 \\
\hline Recruitment - word of mouth & 4 & 5 \\
\hline Recruitment - hired student teachers & 4 & 4 \\
\hline Recruitment - virtual fairs & 3 & 3 \\
\hline Candidate pool - smaller than usual & 8 & 10 \\
\hline Candidate pool - no change & 5 & 5 \\
\hline Candidate pool - expanded geographic reach & 5 & 6 \\
\hline $\begin{array}{l}\text { Candidate pool - less movement of } \\
\text { experienced teachers }\end{array}$ & 4 & 4 \\
\hline Candidate pool - less new teachers & 2 & 3 \\
\hline Candidate qualities sought - technology skills & 8 & 12 \\
\hline Candidate qualities sought - flexibility & 2 & 2 \\
\hline Paper screen- increased importance & 4 & 7 \\
\hline Interviews - socially distanced & 2 & 2 \\
\hline Interviews - virtual & 12 & 12 \\
\hline $\begin{array}{l}\text { Interviews - virtual does not allow for } \\
\text { considerations of body language/facial } \\
\text { expressions }\end{array}$ & 9 & 9 \\
\hline Interviews - developed deeper questions & 9 & 13 \\
\hline Interviews - efficiency of virtual format & 6 & 10 \\
\hline Interviews - problems with virtual format & 6 & 9 \\
\hline Interviews - virtual format created flexibility & 3 & 3 \\
\hline Selection process - streamlined (shorter) & 12 & 12 \\
\hline Selection process - same length & 2 & 2 \\
\hline Selection process - tighter timeframe & 6 & 9 \\
\hline $\begin{array}{l}\text { Selection process - no building tours } \\
\text { problematic }\end{array}$ & 7 & 8 \\
\hline Selection process - on the spot hiring & 3 & 3 \\
\hline Problems - hiring freezes & 5 & 6 \\
\hline Problems - late resignations & 5 & 6 \\
\hline Hiring outcomes - high quality & 12 & 12 \\
\hline Hiring outcomes - not high quality/concerns & 2 & 2 \\
\hline $\begin{array}{l}\text { Future plans - continue virtual interviews or } \\
\text { other virtual elements }\end{array}$ & 10 & 10 \\
\hline Future plans - return to all face to face & 4 & 4 \\
\hline $\begin{array}{l}\text { Future plans - keep deeper interview } \\
\text { questions }\end{array}$ & 8 & 9 \\
\hline
\end{tabular}

KIMBREL / DOI: 10.5929/2021.11.1.1 
While the codes and themes will be explored more deeply in the second level coding results section, an examination of Table 1 creates an overview of the most frequently mentioned topics and issues of importance from the participants' perspective. In general, participants described a difficult recruiting environment resulting in a smaller than usual pool of applicants. Only a few districts could substitute virtual job fairs in the absence of large-scale in-person events, and many school leaders relied on word of mouth and virtual job postings to advertise their vacancies.

Several common codes were also noted in the category of teacher candidate interviews. Most schools used technology platforms to conduct virtual interviews. Participants noted the benefits of virtual interviews such as efficiency and flexibility and mentioned problems such as inappropriate virtual behavior and candidates who had difficulty logging on to the platforms. Also, participants frequently mentioned the loss of conversational interviews and noted that it was difficult to read facial expressions and body language in virtual interviews.

Participants frequently mentioned that the hiring process itself changed, with paper screening becoming more important as selection processes were shortened and conducted on a tighter timeframe. A common theme emerged regarding the inability to conduct building tours with candidates and the opportunity those tours provide to assess teacher candidates informally. Finally, despite the changes in selection processes, school leaders overwhelmingly felt that they had hired the highest quality candidates who could impact student outcomes. Most participants acknowledged that even in a post-COVID environment, they would keep at least some elements of their pandemic era hiring processes.

\section{Second Cycle Data Coding}

The codes that naturally arose from the transcripts (provided in Table 1) were arranged into theme areas according to the research questions for the study to complete the second level coding process. The purpose of second-level coding was to examine the bigger picture represented by the research questions that drove the study and connections to the theoretical framework for the study.

Research question 1: How were teacher hiring processes changed to accommodate school closures and social distancing practices, and how do those changes reflect teacher selection best practices? The codes that align with this research question began with the following prefixes: recruitment, paper screen interviews, and process.

All participants indicated that the pandemic created the need for changes in teacher hiring processes from the early stages of recruitment until the job offer. The cancelation of formal recruitment events was mentioned by nine of the fourteen participants. Some schools held winter and early spring recruitment events before school closures, but most simply canceled large events and college recruitment visits and substituted less formal recruitment measures. Participant $\mathrm{C}$ echoed the thoughts of many when they said, "Usually we hold a recruiting fair in the county and advertise it in the newspapers. We didn't have that at all this year. Our people didn't go to colleges and universities like they usually do. This year it was a lot of word of mouth and people who just went to the website on their own to apply." Only three participants mentioned that virtual job fairs had been created to replace in-person events.

In the absence of formal recruitment events, the expanded importance of the paper screen process to determine which candidates to interview was mentioned seven times by four participants. Participant B commented, "We prepared for interviews in a different way. We dug deeper into resumes and asked questions specifically inspired by what we saw on resumes and applications." Similarly, Participant J said, "We usually get most of our information from the in-person feel, but this year we didn't have that, and we had more time to look at applications. The resumes played a big part so we could find candidates that were a good fit for our teams."

KIMBREL / DOI: 10.5929/2021.11.1.1 
While two participants noted using socially distanced interviews, most opted for virtual interviews using technology platforms. Of the twelve participants that used virtual interviews, seven used Google Meet, two used Microsoft Teams, two used Zoom, and one offered an option of Zoom or Google Meet to candidates. Participants noted a wide variety of benefits of virtual interviews, including ease of sharing digital portfolios by candidates, the efficiency that allowed a large number of interviews to be scheduled on the same day, the flexibility of not requiring the interview team to be in the same room, and ability to schedule during early morning or evenings. Participant A particularly liked that candidates could share portfolios and said, "It was really good because we got to see a lot of their real work that way. Before, we never looked at those things because we didn't have time during our conversations." Efficiency was also a common theme when discussing virtual interviews. Participant J said, "We could have a lot more interviews than if they were in person because we could line them up in a row and move from one to the next so quickly." Similarly, participant K said, "When someone comes face-to-face, you almost have that obligatory thing where they came all this way, so we can't stop you after 15 minutes and virtually we could. We moved on when it was clear it wasn't a fit and saved everyone time."

Nine of the participants noted that the types of questions asked in interviews changed in response to the virtual format. Participant $C$ stated, "The flow of interviews is very different virtually than in person. We usually rely on natural conversation and follow up questions that come up based on our interaction. In-person, it just kind of happens naturally." For these nine participants, the solution for the lack of conversational interviews was to ask different types of questions. Participant $\mathrm{H}$ said, "It made me pay more attention to ask deeper questions to see if it's something that they really understand and can do or just something they have a surface understanding of." Participant A said, "We started using a set of questions this year that really dig into the core values of the person," and participant D said, "Some people were really rigid and so to get longer responses we tried giving them more situations and asked what they would do or how they would respond." Finally, participant K summed it up this way, "In the past, I had hired people that wowed me in person, and then it was kind of like fool's gold when they came to work. I feel that the questioning I used in the virtual interviews avoided this, and I got more quality candidates than ever before."

Despite the benefits of virtual interviews, some problems did arise. "We had everything from cats jumping across the screen to kids screaming in the background, and one lady doing an interview from her car while she was driving to Florida for a vacation. We also saw some questionable wardrobe choices," said Participant I. Participant D noted problems logging on t virtual interviews, "We did have some people with trouble signing on to Google Meets because they couldn't figure out how to use it even though we sent directions. This told me that this may be a person who has trouble teaching virtually."

The most frequent complaints from participants regarding the virtual interview format were about their lack of ability to have naturally occurring conversations in which body language and facial expressions were key elements. Similarly, seven participants identified the absence of school building tours for candidates as problematic. Many comments reflected these complaints, including one from Participant K, "For me personally, I get a lot out of interviews by tone of voice and the look on someone's face. You miss that in a virtual interview." Similarly, participant F said, "There is something to be said for being in the same room with someone and getting a feel for their personality. The handshake, eye contact, and body language are things you can't get electronically." Participants perceived one of the biggest losses to the in-person interview format to be the lack of a school building tour. Participant A said, "Just being with someone and showing them the building, you can pick up on things and see how well they do with small talk."

While most of the feedback from participants focused on the interview component, there were some common perceptions about changes to other elements of the process, including hiring delays that 
caused tight timeframes, streamlined processes, and immediate hiring after one interview. The most common process change mentioned was that teacher selection timelines were shortened. Participant $F$ noted, "We held fewer rounds of interviews because an effective part of using Microsoft Teams was that we could put more people on the panel than we could face to face." Participant $\mathrm{N}$ shortened the process to be able to move quickly after a hiring freeze was lifted, "We had a non-existent second round of interviews. Once we were finally able to start interviewing, we had to do it fast to get our candidates before they were hired by another school." Participants appreciated the quick hiring processes but also understood the potential peril of fast decision making. "I would warn principals that you don't need to make a decision in the moment like we did. When you become a prisoner of the moment, you start to give things up and lose the integrity of the process a little bit," said participant D.

Research question 2: From the perspective of school administrators, how effective were hiring processes to identify high-quality teachers during the spring and summer of 2020 ? The codes that align with this research question were those that began with the following prefixes: pool, problems, candidate qualities sought, hiring outcomes.

There was a common perception among participants that the 2020 hiring season produced a smaller pool of candidates than in the past few years. However, it should be noted that the perception of the candidate pool seemed to depend on the characteristics of the school. Several participants shared that their high performing school or school located in a desirable location had no trouble attracting an abundance of candidates. Perceptions of the types of candidates in the pool varied as well. Several participants speculated that there were fewer experienced teachers in the pool because teachers may be unwilling to risk leaving their positions to interview in a new school during a global pandemic. Another frequent theme about the candidate pool was the increase of candidates outside the school's immediate geographic region. Participant E stated, "We hired from all over the country. Of the 15 we hired, seven were from out of state, and that has never been the case in the past."

Many participants discussed problems that interfered with their ability to recruit and select the best teachers, including late resignations and retirements related to the pandemic and hiring freezes. Participant $L$ shared, "We had a ton of late resignations because of personal health issues or the health of family members. I had to fill a lot of positions in the last few weeks before school, and there weren't many candidates left to choose from." Hiring freezes also created a problem with hiring the best candidates. Participant B stated, "We held our interviews but couldn't offer the positions because of the hiring freeze. By the time it was lifted, it got tricky because most of them had taken other positions, and we had to start again late in the game."

The qualities sought in candidates also shifted in response to the pandemic. Eight participants described the necessity of finding teachers who were proficient with technology. Participant E stated, "We were looking for people who had savvy with technology and were able to manipulate the technology because we knew we were probably coming back this year to at least some digital instruction." As stated earlier, the virtual hiring process provided an authentic assessment of candidates' technology skills. Participant $\mathrm{H}$ stated, "It revealed to us that if we are hiring someone who can't log into Google Meets, it's going to be very difficult to teach virtually using the same platform." Similarly, participant E said, "In a regular interview, we are all professionally dressed, and the candidate tells us all about how they can use google and differentiate, but then we find out that they really don't know how. The virtual interview changed that dynamic." Finally, participant $\mathrm{M}$ stated, "I think this was our best hiring year because we could see if someone was a good fit. If I can't be engaged with them on the virtual meeting as an adult, a 13-year-old definitely won't be."

Despite shortened hiring processes and tight timelines, ultimately, twelve out of fourteen participants felt they hired high-quality teachers. Twelve of the 14 participants felt that their processes allowed them

KIMBREL / DOI: 10.5929/2021.11.1.1 
to select the best candidates and the comments indicate high confidence in the new teachers. Comments from participants included: "We are so fortunate, and we nailed it on the people that we hired;" "word on the street is that they are off to an awesome start;" "I think we hit the jackpot with most of our teachers, they are fabulous;" and, "I'm especially happy with our new hires from outside the state." Only two participants indicated any trepidation about their new teachers.

Research Question 3: How do school administrators anticipate that the virtual teacher hiring experience will change future teacher selection processes? The code that aligned with this research question: future plans.

While school leaders were forced to make quick and unexpected changes in response to COVID19 , ten of the fourteen participants in this study found enough benefit in the new practices that they planned to make permanent changes in their teacher selection processes based on their experience. Participant B expressed a desire to continue with virtual interviews to accommodate busy schedules, "I don't necessarily think that Zoom was all bad, it allowed us to be efficient and at times when someone from the school wasn't available, we were able to bring someone in from the district if we needed more people on the interview panel. I'm not at all opposed to that practice in the future." The benefits of virtual interviews were echoed by Participant A, "In the future, Google is still a good option for us even if the pandemic is over. We interviewed a lot of candidates from out of state and other parts of the state. Using Google allowed us to get great candidates who would never have traveled to the district in the past." Participant $\mathrm{H}$ plans to implement a hybrid approach, "I would start with digital interviews and then call them in for a second interview. It just made the process go a lot faster, and it made us pay more attention to detail on the resume." Several other participants mentioned the benefit of cutting virtual interviews short when they were not going poorly and virtual communication among the panel of interviewers during the interview that is not possible during a live interview.

Eight participants indicated that they plan to continue to use the types of questions that were developed for the virtual interviews, even if they return to a face-to-face process. Participant A said, "The type of process is less important to me than the kinds of questions we ask. I'm going to focus on using the kinds of questions that really get at a candidates' values and what they really can do to help students learn." Similarly, participant K said, "We had to use more questions about situations and ask people what they would do if some specific thing happened. It gave us excellent information about how they will work instead of a dog and pony we sometimes get. We are going to keep using those questions next year." Participants also saw the virtual interview's value as an authentic assessment of candidates' ability to teach virtually. Participant $D$ summed it up by saying, "I don't' think virtual teaching is going to completely go away now that we have done it for the pandemic. We are going to need people who are very comfortable with technology, and the virtual interviews were a really good test of their skills."

The desire for the building tour portion of the interview process was also a theme when participants discussed future selection processes. Participant $L$ said, "No matter what we do, we need to have a building tour so that our candidates understand our school and our culture." Several other participants shared creative ways to add a virtual tour to the process if school closures persist. Participant $G$ said, "Maybe we could do a video tour of our school and then ask the candidate to make a video that is a response to it."

\section{Discussion}

The data gathered from the semi-structured interviews revealed a variety of themes. The themes are organized in this discussion by expected results, unexpected results, and results of theoretical importance.

KIMBREL / DOI: 10.5929/2021.11.1.1 


\section{Expected Results}

School leaders face various challenges during a typical hiring season, so it was expected that those challenges would be exacerbated during a time of crisis. The school leaders' responses in this study revealed that the hiring processes used during the spring and summer of 2020 changed in predictable ways. The teacher hiring season typically begins with recruiting fairs held in the early spring in large indoor arenas where representatives from many schools and a large number of candidates gather. Simultaneously, school personnel managers visit college campuses to recruit candidates who are about to graduate as certified teachers. This study revealed that, as expected, those in-person events were canceled and, in most cases, not replaced with virtual events. In the absence of large-scale recruitment fairs and recruiting on college campuses, school leaders reported reliance on word of mouth, hiring their student teachers, and job postings to build their candidate pools.

The growing problem of teacher shortages, especially in high poverty schools, have been well documented over the past decade. In a report from The Learning Policy Institute, Sutcher et al. (2016) theorize that teacher shortages are a function of excessive teacher attrition and decreasing numbers of students who complete teacher preparation programs. They claim that as a result, large numbers of schools cannot fill positions, especially in areas of high poverty. One would expect that the pandemic only exacerbated the shrinking teacher candidate pool and the results of this study confirm these problems. School leader perceptions of the pool of candidates were dependent on the location and performance of the school. High performing schools in desirable communities reported no changes in the candidate pool, whereas leaders in rural schools and high poverty areas reported difficulty finding qualified teachers, especially in special education.

Given that schools delivered instruction to students virtually through various technology platforms, it is not surprising that most participants in this study opted to interview teacher candidates virtually using the same technology. School leaders also reported their desire to hire teacher candidates proficient enough with technology to deliver virtual instruction to students effectively, and that virtual interviews created an authentic assessment of candidates' technology skills. Candidates could demonstrate, rather than discuss their technology proficiency by logging into and participating in a virtual interview.

There were other predictable advantages to virtual interviews echoed throughout this study. Participants noted streamlined processes that allowed more people to participate in interview panels, schedule a large number of interviews in a short amount of time, and convenience to the candidate who did not have to travel to the school. Participants noted that they had an easier time cutting interviews short without guilt because candidates did not take the time to travel to their school. Many of the problems noted with virtual interviews reflected the universal experience by others during the pandemic, including individuals who did not know how to log in, disruptions in interviews due to issues in candidates and interviewers' homes, and individuals who seemed awkward in the virtual format.

Finally, as is typical, the school administrators who participated in this study felt quite optimistic about the teachers they hired despite a variety of concerns, including late resignations and consequent late hiring, shortened processes, and immediate hiring of candidates after one interview. Before the pandemic, principals reported high levels of confidence in their ability to select high-quality teacher candidates, regardless of the extent to which their process reflected best practices for hiring described in the literature (Kimbrel b, 2019). Given this previous research, principals' continued optimism regarding their hiring ability despite the obstacles presented by the pandemic was expected. 


\section{Unexpected Themes}

The results of this study revealed unexpected themes about the benefits of the hiring process during school closures. It was anticipated that the teacher candidate pool may be smaller than usual, but that virtual interview processes resulted in more applications from candidates outside the immediate geographic region was unanticipated by both the researcher and the participants. The virtual interview process also allowed school leaders to add more school and district staff members to panel interviews, thereby eliminating the need for second interviews. Finally, an unexpected outcome of the hiring process during school closures was the heightened importance of the paper screening process to determine which candidates to interview. While research indicates that some information included in applications such as grade point average and the specific college attended have little influence on teacher job performance (Buddin \& Zamarro, 2009; Chingos \& Peterson, 2011), the paper screen portion of the selection process is important to determine if minimum qualifications such as certification have been met. A careful review of applications can also provide insight into candidates' writing skills and attention to detail and specific areas of concern that can guide interview questions.

\section{Themes with theoretical importance}

Given the well-documented connection between high-quality teachers and student outcomes (Darling-Hammond, 2000; Hattie, 2009; Marzano, 2003), creating teacher selection processes that effectively identify the most skilled candidates is an essential element of school improvement even during times of crisis. This study's results included several themes of theoretical importance for researchers and practitioners who seek to improve teacher quality. In general, virtual interviews created conditions where selection processes that do not predict teacher success, such as casual conversations with candidates without structured questions (Moore, 2017), were more difficult to implement. School leaders expressed concern that virtual interviews did not allow them to see and interpret candidates' body language and facial expressions or to have conversational interviews that they had previously relied upon to select teachers whom they felt were a good fit for their school culture. While, this finding does confirm previous research that principals often select teachers based on subjective interpretation and perceptions of the candidate's character (Bourke, 2012), the extent to which school leaders lamented the loss of casual conversation was surprising. Also, an unexpected but important theme arose regarding school leaders' perceptions of school tours as a vehicle to assess candidates as they engaged in small talk and casual conversation. Again, the inability to rely upon the most subjective means to assess candidate's skills and school leaders and unawareness of the decades of research regarding these measures' ineffectiveness were notable.

When school leaders were faced with circumstances where in-person interviews were not possible, they quickly discovered that they could no longer rely on first impressions, the candidate's enthusiasm level, small talk, and facial expressions to make judgments about candidates. The adoption of virtual interviews forced the use of practices more closely aligned with selection science research, including redesigned interview questions that seek to uncover candidate values or pose a situation in which the candidate must explain their teaching behaviors (Hamdani, Valcea, \& Buckley, 2014; Macan, 2009; Moore, 2017). Many leaders also expressed that teaching artifacts included in digital portfolios became an important part of the virtual interviews for the first time. Leaders admitted that when these types of portfolios were shared during in-person interviews as hard copies, they preferred to focus more on their engagement in the conversation than the artifacts in the portfolio. Finally, this study found that the act of successfully logging into and engaging in a virtual interview became an authentic assessment of a candidate's technology skills. This was especially important because virtual instruction occurred on the same platforms as virtual interviews.

KIMBREL / DOI: 10.5929/2021.11.1.1 
Virtual interviews created a situation in which school leaders changed their practices to adapt to the situation and, as a result, unknowingly, adopted teacher selection processes that were more likely to identify candidates with the greatest likelihood to impact student achievement. This study also revealed that school leaders found benefits in these new practices and planned to continue them in the future. Specifically, interviewing more candidates in less time, expanding the geographic reach beyond their school boundaries, and flexibility for candidates and school teams were identified as reasons to continue virtual interviews even without school closures. A smaller number of participants understood that the revision of questions, authentic tasks, and examination of teaching artifacts resulted in valuable data regarding candidates' skills and abilities.

\section{Limitations}

As with most qualitative research, this study is limited by the small number of participants. Similarly, the specific geographic area of participants may limit the generalizability of the results to other regions. Participants in this study were explicitly asked about their hiring perceptions during the COVID19 pandemic in the spring and summer of 2020. Given the unusual and extreme circumstances of this time, the results of this study may not be generalizable to other and less severe crises. Finally, because there has not been a global pandemic that forced school closures since the $1918 \mathrm{flu}$, there is no bank of literature available to compare the results of this study.

\section{Conclusion}

In the absence of conversational interviews in which judgments are made about candidates by first impressions, body language, tone of voice, and facial expressions, school leaders were forced to adopt more reliable selection practices. This study's results indicate that virtual interviews created conditions under which school leaders screened resumes and application paperwork more carefully and created interview questions to uncover candidate values and previous teaching behaviors. School leaders also found value in the opportunities created by virtual interviews for authentic assessment of the candidates' technology skills and presentation of teaching artifacts when candidates shared digital portfolios. School leaders did not intentionally align their new selection processes with research-based best practices, but these changes were made as a response to circumstances beyond their control.

This study also found that administrators were aware of the practical value of the changes made to their hiring processes, and most indicated that they intended to maintain at least some of their new practices. The school leaders appreciated virtual interviews' convenience and efficiency and mentioned concrete benefits such as expanded geographic regions from which to hire teachers. While the participants had a sense that their deeper levels of questioning and opportunities for authentic assessment were beneficial, they did not connect those changes in their practice to research or an understanding of the benefits of removing subjectivity from the interview process or as a deliberate use of more reliable methods to determine the skill level of the teacher candidate. Participants lamented the loss of subjective and unreliable measures of teacher skill such as conversation, small talk that occurs on school tours, facial expressions, and level of enthusiasm.

The implications of this study for researchers, those who prepare school leaders, and practitioners are clear. Improvements in student outcomes are possible when high-quality teachers are employed and retained by school leaders. Identifying and hiring effective teachers are essential elements of school improvement, and yet, most school leaders are unaware of best practices for teacher selection and how to remove subjectivity from the hiring process. A renewed emphasis on effective hiring practices should be pursued in leader preparation programs and through professional development initiatives in school districts. There are also abundant opportunities for researchers to continue to develop and test valid and reliable teacher selection instruments and processes that can be made readily available to school leaders.

KIMBREL / DOI: 10.5929/2021.11.1.1 


\section{References}

Bourke, K. B. (2012). Public secondary school principals' perspectives on teacher hiring: What matters most? (Publication No. ED551731). [Doctoral dissertation]. ProQuest, LLC.

Buddin, R., \& Zamarro, G. (2009). Teacher qualifications and student achievement in urban elementary schools. Santa Monica, CA: Rand Corporation. https://doi.org/10.1016/j.jue.2009.05.001

Cannata, M., Rubin, M., Goldring, E., Grissom, J. A., Neumerski, C.M., Drake, T. A., \& Schuermann, P. (2017). Using teacher effectiveness data for information-rich hiring. Educational Administration Quarterly, 53(2), 180-222. https://doi.org/10.1177/0013161x16681629

Chavez, N. \& Moshtaghian, A. (2020, May 7). 48 states have ordered or recommended that schools don't reopen this academic year. CNN. https://www.cnn.com/2020/04/18/us/schools-closedcoronavirus/index.html

Chingos, M. M., \& Peterson, P. E. (2011). It's easier to pick a good teacher than to train one: Familiar and new results on the correlates of teacher effectiveness. Economics of Education Review, 30(3), 449-465. https://doi.org/ 0.1016/j.econedurev.2010.12.010

Cresswell, J.W., \& Cresswell, J.D. (2018). Research Design: Qualitative, Quantitative, and Mixed Method Approaches $\left(5^{\text {th }}\right.$ ed). Sage.

Crosby, O. (2000). Employment interviewing: Seizing the opportunity and the job. Occupational Outlook Quarterly, 44(2), 14-21. https://www.bls.gov/careeroutlook/2016/article/employmentinterviewing.htm?view full

Darling-Hammond, L. (2000). Teacher quality and student achievement: A review of state policy evidence. Education Policy Analysis Archives, 8(1). https://doi.org/10.14507/epaa.v8n1.2000

Engel, M. (2013). Problematic preferences? A mixed method examination of what principals' preference for teacher characteristics in Chicago. Educational Administration Quarterly, 49, 52-91. https://doi.org/10.1177/0013161x12451025

Goldhaber, D., Grout, C., \& Huntington-Klein, N. (2014). It's selective but is it effective? Exploring the predictive validity of teacher selection tools. [Issue brief]. Center for Educational Data \& Research. http://www.cedr.us/papers/working/CEDR\%20Policy\%20Brief\%202014-9.pdf

Hamdani, M. R., Valcea, S., \& Buckly, R. M. (2014). The relentless pursuit of construct validity in the design of employment interviews. Human Resource Management Review, 24(2), 160-176. https://doi.org/10.1016/j.hrmr.2013.07.002

Hattie, J. (2009). Visible learning: A synthesis of over 800 meta-analyses related to achievement. New York, NY: Routledge.

Jacob, B. (2016). The power of teacher selection to improve education. (Report No. 12, Volume 1) Evidence Speaks Reports Economics Studies at Brookings. https://www.brookings.edu/research/thepower-of-teacher-selection-to-improve-education

Joyce, M. P. (2008). Interviewing techniques used in selected organizations today. Business Communication Quarterly, 71(3), 376-380. https://doi.org/10.1177/1080569908321427

Kersten, T. (2010). Using a group process in teacher hiring. School Administrator, 67(8), 36-37. https://search.ebscohost.com/login.aspx?direct=true\&AuthType=ip, shib\&db=eft\&AN=53283 $\underline{412 \& \text { site }=\text { ehost-live }}$

KIMBREL / DOI: 10.5929/2021.11.1.1 
Kimbrel, LA (2019a). The disconnect between research based best practices and processes used by school principals. Administrative Issues Journal: Connecting Education, Practice, and Research, 9(2), 1227. https://doi.org/10.5929/9.2.2

Kimbrel, LA (2019b). Teacher selection: School principal hiring practices, level of training, and confidence. International Research in Education, 7(2), 106122. https://doi.org/10.5296/ire.v7i2.15332

Konoske-Graf, A., Partelow, L., Benner, M. (2016, December 22). To attract great teachers, school districts must improve their human capital systems. Center for American Progress. https://www.americanprogress.org/issues/education-k-12/reports/2016/12/22/295574/toattract-great-teachers-school-districts-must-improve-their-human-capital-systems/

Kraft, M., \& Gilmour, A. (2017). Revisiting the widget effect: Teacher evaluation reforms and the distribution of teacher effectiveness. Educational Researcher, 46(5), 234-249. https://doi.org/10.3102/0013189×17718797

Loeb, S., Beteille, T., \& Kalogrides, D. (2012). Effective schools: Teacher hiring, assignment, development, and retention. Education Finance and Policy, 7(3), 269-304. https://doi.org/10.3386/w17177

Marzano, R. (2003). What works in schools: Translating research into action. Alexandria, VA: ASCD.

Merriam, S., \& Tisdell, E. (2016). Qualitative research: A guide to design and implementation. Jossey-Bass.

Mertz, N. (2010). Teacher selection and school leader effects. Journal of School Leadership, 20(2), 184207. https://doi.org/10.1177/105268461002000204

Miles, M.B, Huberman, A.M., \& Saldana, J. (2020). Qualitative Data Analysis: A Methods Sourcebook. Sage.

Moore, D. A. (2017). How to improve the accuracy and reduce the cost of personnel selection. California Management Review, (60)1, 8-17. https://doi.org/10.1177/0008125617725288

Murnane, R. J., \& Steele, J. L. (2007). What is the problem? The challenge of providing effective teachers for all children. The Future of Children, 17(1), 15-43. https://doi.org/10.1353/foc.2007.0010

National Center for Education Statistics (n.d.). School staffing survey. https://nces.ed.gov/surveys/sass/

Nixon, A., Packard, A., Kimbrel, L, \& Nhekairo, N. (2020). Principals tackle teacher performance. AASA $\begin{array}{lllll}\text { Journal of Scholarship } & \end{array}$ https://www.aasa.org/uploadedFiles/Publications/JSPFall2020.pdf

Mertz, N. (2010). Teacher selection and school leader effects. Journal of School Leadership, 20(2), 184207. https://doi.org/10.1177/105268461002000204

Pillsbury, P. (2005). Only the best: hiring outstanding teachers. Leadership, 35(2), 36-38. https://eric.ed.gov/?id=EJ727827

Roulston, K. (2010). Reflective interviewing: A guide to theory and practice. https://doi.org/10.4135/9781446288009

Saldana, J. (2016). The coding manual for qualitative researchers $\left(3^{\text {rd }}\right.$ ed). Sage.

Sutcher, L., Darling-Hammond, L. \& Carver-Thomas., D. (2016). A coming crisis in teaching: Teacher supply, demand, and shortages in the US. Learning Policy Institute. https://learningpolicyinstitute.org/product/coming-crisis-teaching

KIMBREL / DOI: 10.5929/2021.11.1.1 
Seagrest Purkiss, S. L., Perrewe, P. L., Gillespie, T. L., Mayes, B. T., \& Ferris, G. R. (2006). Implicit sources of bias in employment interview judgments and decisions. Organizational Behavior and Human Decision Processes, 101(2), 152-167. https://doi.org/10.1016/j.obhdp.2006.06.005

\section{About the Author}

Dr. Laurie Kimbrel, Ed.D. (lkimbrel@westga.edu) is currently an Assistant Professor in the Department of Leadership, Research \& School Improvement at the University of West Georgia. She previously had a 27 -year career in K12 public education where she served as a teacher, principal, and superintendent. 